\title{
CFD INVESTIGATION OF MECHANICAL SEAL FOR IMPROVE THERMAL PROPERTY BY USING DIFFERENT COMPOSITE MATERIAL IN MATING RING
}

\author{
Lalit Kumar Bajirao Chauhan ${ }^{1}$, Sandeep Kumar Duran ${ }^{2}$ \\ ${ }^{l}$ M.Tech Research Scholar, Department of Mechanical Engineering, Lovely Professional University, India \\ ${ }^{2}$ Assistant Professor, Department of Mechanical Engineering, Lovely Professional University India
}

\begin{abstract}
Heat accumulation is the major cause that leads to change in material properties affecting seal performance, hence heat dissipation is required. The paper constitutes the method to improve the heat transfer rate in mechanical seal for decreasing the interface temperature of the seal face. Different factors that affect the performance of mechanical seal are friction, wear and its thermal characteristics. Concept of Fourier's law of heat conduction through cylindrical surfaces is used for optimizing the heat transfer rate. Composite material for mating ring with different thermal conductivity is used to increase the heat transfer rate to enhance the seal performance. Properties of Carbon graphite and silicon carbide were used in the Simulation and simulation was performed using ANSYS Mechanical Module 14.5 and CFD FLUENT. Simulated values for the mating ring made of single material and the composite ring was observed and compared. The interface temperature of the mating ring is effectively decreased, due to increase in heat dissipation.
\end{abstract}

Keywords - Frictional heat, Interface temperature, Leakage, Mating ring, Mechanical seal, Thermal conductivity and Thermal effects.

\section{INTRODUCTION}

Mechanical seal, leakage control device is the most important industrial components widely used to prevent leakage of fluids to the surrounding. All mechanical seal leaks but can be minimized. It is used for sealing pressurized fluids in rotating machines such as pumps, propeller shafts used in defence, power plants, agitators, dryers and compressors. Seal basically consist of a rotating part (primary) mounted on to the shaft and stationary (mating) part being fixed to the housing. Primary ring, axially pressed against the mating ring are kept in contact using spring as shown in figure 1 . While operation the primary ring rotates against the stationary mating ring generating interfacial frictional heat. Varieties of mechanical seal, ranging from simple single spring design to considerably more complex cartridge type seal are available. The design, arrangement and material of the seal are basically determined by the pressure, temperature, speed of rotation and the product being sealed. Factors on which the leakage rate of mechanical seal depends are surface roughness of the seal face, flatness of the seal faces, speed of rotation, shuddering and stability of the pump, diameter of the shaft, temperature, viscosity and the type of pumped medium, pressure of the pump, seal and pump installation. Under Dry conditions wear out on the contact surfaces is the major cause of failure [1]. Conduction and convection are the two modes of heat transfer taking place during operation. The heat conduction occurs as heat flows through the primary ring and the mating ring. Heat generation in mechanical seal is shown in figure 2 . The thermal conductivity of the material is very important for determining heat transfer.

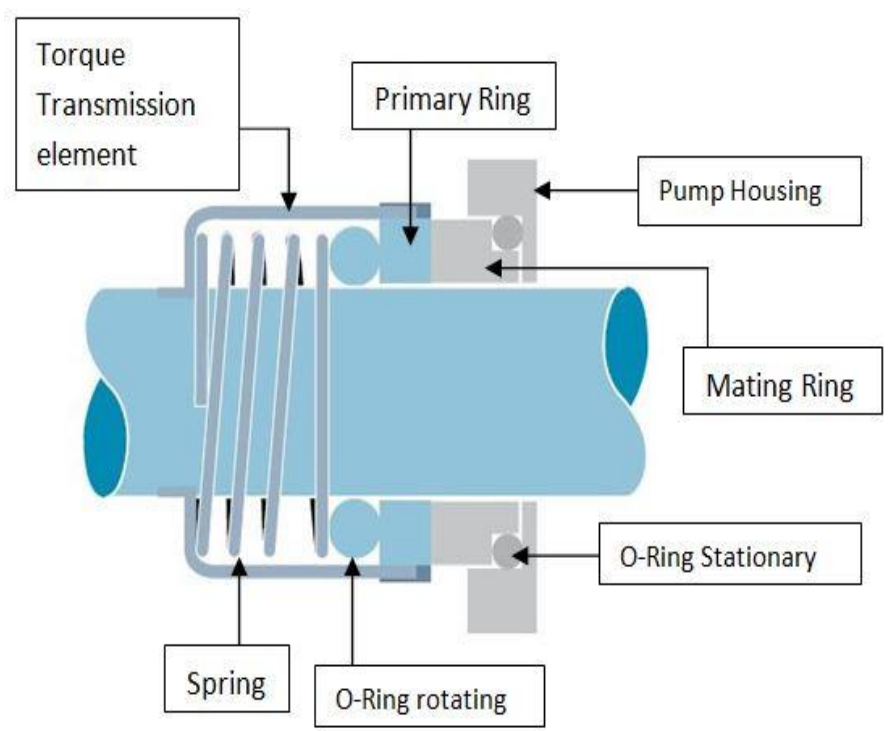

Fig-1: Major Components of mechanical seal.

In addition, the heat generated between the interfaces is dissipated to the flush fluid through convection process. Superior heat transfer coefficient and large wetted area is required to eliminate the generated heat more effectively. Good operating conditions are achieved when the seal faces are partially separated by a thin lubricating fluid film (a fraction of micrometer $\sim 0.00025 \mathrm{~mm}$ ). The heat transfer can be enhanced by increasing the solid fluid contact area [2]. 


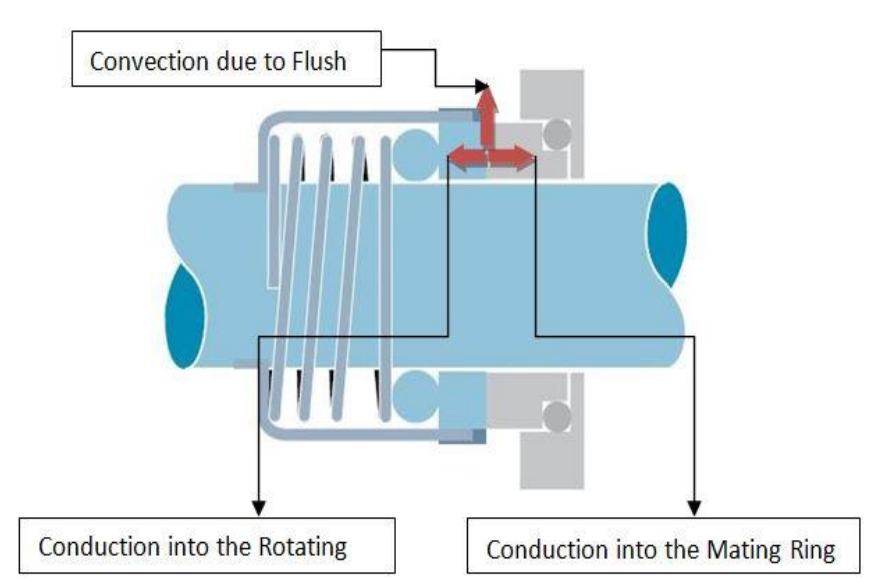

Fig-2: Heat generation in mechanical seal.

According to Lebeck [3], the performance and the behaviour of a mechanical seal face are mostly influenced by the thermal characteristics. The seal rings rub against each other with a very thin lubricating film in between them. The pressure distribution in the lubricating film is composed of hydrostatic and hydrodynamic contribution. The pressure difference between the pumped medium and the atmospheric, give rise to hydrostatic pressure and is generated when the shaft starts rotating separating the seal faces and allowing the fluid to enter the gap. When the pump runs, hydrodynamic pressure is generated due to pumping action. Waviness leads to the generation of hydrodynamic pressure, increasing the lubricating film thickness that result in the higher leakage rate. Lubrication conditions can be modified according to the operating conditions of the seal. Lebeck proposed the following three lubrication regimes

Full film lubrication: It is obtained when the pressure in the sealing gap is sufficiently high. In this type of lubrication the seal develops a significant film thickness, and the integral load is supported by the fluid pressure. Due to thick lubrication there is no contact between the seal faces and the friction is also low.

Mixed lubrication: It is the most common mode in which the seal operates. Mixed friction is characterized by the fact that a part of the load is carried out by the mechanical contact, even the bulk of the load may be carried by fluid pressure.

Boundary lubrication: This condition arises if the lubricant quantity is low or the operating speed is so low that the fluid pressure is not properly developed. A small fraction of load is supported by the fluid pressure. However maximum contact between the two face seal leads to high frictional heat generation rates.

Carbon graphite a mixture of hard carbon and graphite is the most commonly used material for the manufacturing of primary ring due to its high anti friction properties. Tungsten carbide, stainless steel, silicon carbide, ceramics are used for the manufacturing of mating ring. Low friction, higher hardness, high thermal conductivity, higher resistance to corrosion and high heat conductivity are the few properties on which the selection of seal face material is performed. Friction between the two seal faces is the major cause of heat generation [4]. At elevated temperature the seal face deforms and alter its geometry [5].

Different heat augmentation techniques were performed to conquer seal failure problems. Embedding Micro heat exchanger below the surface of mating ring improves heat transfer in mechanical seal as described by Kountouris [6]. Etsion et al.[7] in his study of laser textured micro surface structure with micro pores showed an improvement in seal performance. Thermally induced radial taper, induced waviness, heat checking and hot spotting, blistering, coking and crystallization are the thermal effects on seal face as described by Pascovici and Etsion [8]. Seal face material should be properly selected while designing. The combination of mechanical seal face material has an important consideration in heat transfer and seal failure as stated by Buck [9]. He showed that the combination of different materials have different results for heat transfer. M.M Khonsari [10] found that heat transfer can be improved by increasing the surface area of the seal face. Using dimples over the circumference of mating ring the temperature of the ring can be reduced by $10 \%$. Heat pipe has more capacity to absorb heat from the contact face and transfer it to the external surface to the flush fluid. Nian Xiao and M.M Khonsari [11] showed a reduction in interface temperature using built in heat pipe in the mating ring. Z Luan and M.M Khonsari [12] found that the mean fluid thickness depends on the Surface roughness. Film thickness can be used for determining the leakage rate and the dissipated power. Philips et al. [13] in his study observed the impact of thermal distortions on seal. Torque, thermal gradient and fluid flow pattern also enhance the seal performance.

\section{GEOMETRICAL AND OPERATING}

\section{CONDITIONS}

Material selection is an important consideration while designing mechanical seal. For good results appropriate material should be selected. For simulation mating ring made of Carbon graphite in first condition and a mating ring of composite material of carbon graphite and silicon carbide are selected. The simple and composite mating rings shown in the figure 3 were used for analysing the heat transfer through them. Carbon graphite is selected for simple mating ring, fixed on the shaft by means of support, due to its superior wear and corrosive properties. For Composite mating ring carbon graphite for the inner section of the ring and silicon carbide for the outer section of the ring were used. The fluid used is water. Thermal properties of fluid are presented in table 1 . The operating conditions and the dimensions of the mechanical face seal are detailed in table 2 and the basic thermal properties of the material used for seal face are shown in table 3 . 


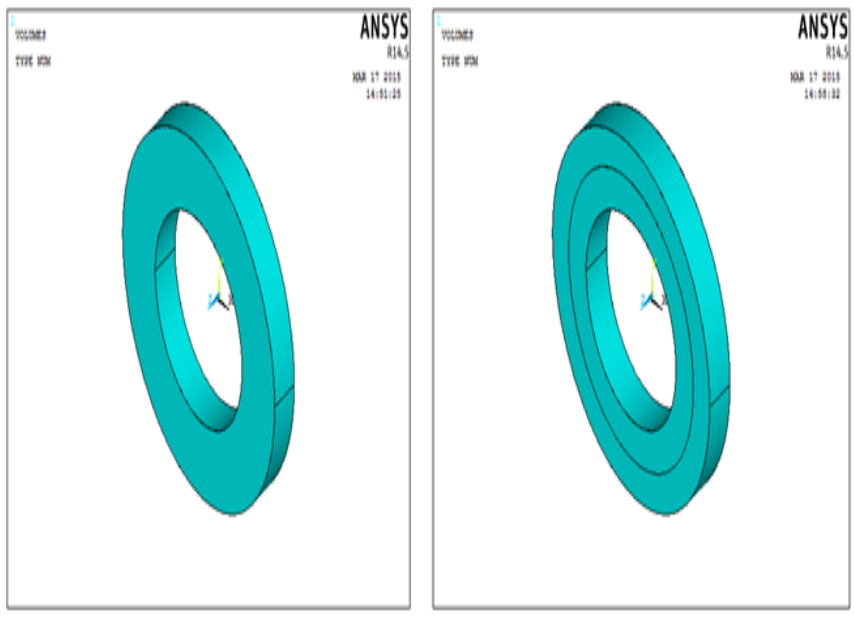

Fig-3: Simple mating ring and Composite mating ring

Table-1: Fluid Properties

\begin{tabular}{|l|l|}
\hline Density $\left(\mathrm{kg} / \mathrm{m}^{3}\right)$ & 997.65 \\
\hline Specific heat $\mathrm{C}_{\mathrm{p}}\left(\mathrm{J} / \mathrm{g}{ }^{\circ} \mathrm{C}\right)$ & 4.177 \\
\hline Thermal conductivity ' $\mathrm{k}$ ' $(\mathrm{W} / \mathrm{m}-\mathrm{K})$ & 0.58 \\
\hline Dynamic viscosity $\mu(\mathrm{Pa} \mathrm{s}) * 10^{-3}$ & 0.75 \\
\hline
\end{tabular}

Table-2: Dimensions and Operating Conditions.

\begin{tabular}{|l|l|}
\hline Angular velocity $\omega(\mathrm{rpm})$ & $500-1500$ \\
\hline Fluid pressure $(\mathrm{KPa})$ & 50 \\
\hline Inlet fluid temperature $\left({ }^{\circ} \mathrm{C}\right)$ & 22 \\
\hline Outlet fluid temperature $\left({ }^{\circ} \mathrm{C}\right)$ & 70 \\
\hline Mass flow rate $(\mathrm{Kg} / \mathrm{s})$ & $0.003-0.015$ \\
\hline Inner radius of mating ring $(\mathrm{mm})$ & 22 \\
\hline Outer radius of mating ring $(\mathrm{mm})$ & 38.5 \\
\hline Thickness of the ring $(\mathrm{mm})$ & 10 \\
\hline Axial clearance $\mathrm{H}(\mathrm{mm})$ & 12.2 \\
\hline
\end{tabular}

Table-3: Material Thermal Properties and Assignment.

\begin{tabular}{|l|l|l|l|l|}
\hline Material & $\begin{array}{l}\text { Thermal } \\
\text { Conductivit } \\
\mathbf{y} \text { 'k' } \\
(\mathbf{W} / \mathbf{m} \text { k) }\end{array}$ & $\begin{array}{l}\text { Density } \\
\text { '分 } \\
(\mathbf{g m} / \mathbf{m 3})\end{array}$ & $\begin{array}{l}\text { Poisson } \\
\text { Ratio }\end{array}$ & $\begin{array}{l}\text { Speci } \\
\text { fic } \\
\text { Heat } \\
(\mathbf{J} / \mathbf{K g} \\
\mathbf{K})\end{array}$ \\
\hline $\begin{array}{l}\text { Carbon } \\
\text { graphite }\end{array}$ & 17 & 1610 & 0.23 & 771 \\
\hline $\begin{array}{l}\text { Silicon } \\
\text { carbide }\end{array}$ & 120 & 3100 & 0.14 & 750 \\
\hline $\begin{array}{l}\text { Stainless } \\
\text { Steel }\end{array}$ & 15.2 & 7870 & 0.265 & 490 \\
\hline
\end{tabular}

\section{NUMERICAL MODEL}

Seal is designed using Creo Parametric 14.0. ANSYS Mechanical Module 14.5 and CFD FLUENT were used for numerical simulation of mating ring with simple and composite mating rings. The problem is considered to be axisymmetric. The Mechanical seal is shown in figure 4 . Surface meshing with housing and volume meshing without housing and boundary conditions used for numerical simulation are shown in figure 5(A) and 5(B). For getting higher accuracy of the solution fine tetrahedral meshing was done. Boundary conditions such as pressure outlet, velocity and the inner and outer surfaces of seal face are defined by appropriate boundary conditions to simulate a proper $3 \mathrm{D}$ model using ANSYS ICEM CFD 14.0 software.

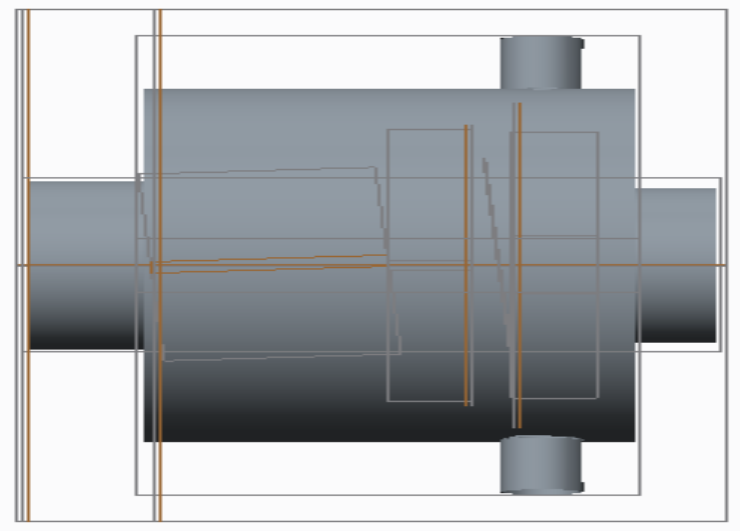

Fig-4: Mechanical seal.

Fourier's law of heat conduction in cylindrical surfaces shown in the equation states, heat transfer rate ' $Q$ ' is directly proportional to the thermal gradient and is inversely proportional to the resistance offered to the heat flow by the material being used. The negative sign indicates the direction of flow of heat from higher to lower level. Resistance ' $R$ ' depends on the logarithm of the ratio of the radius and the thermal conductivity ' $\mathrm{K}$ ' of the material. The thickness of the mating ring is denoted by 'L'. Higher the thermal conductivity, higher is the heat transfer rate. First the heat transfer rate is observed for the mating ring of carbon graphite. In the next segment a composite mating ring made of carbon graphite and silicon carbide was evaluated.

$$
Q=-k A \frac{\partial T}{\partial x}
$$

Also,

$$
Q=\frac{\partial T}{R}
$$

Where

$$
R=\frac{\ln \left(\frac{r 2}{r 1}\right)}{2 \pi K L}
$$




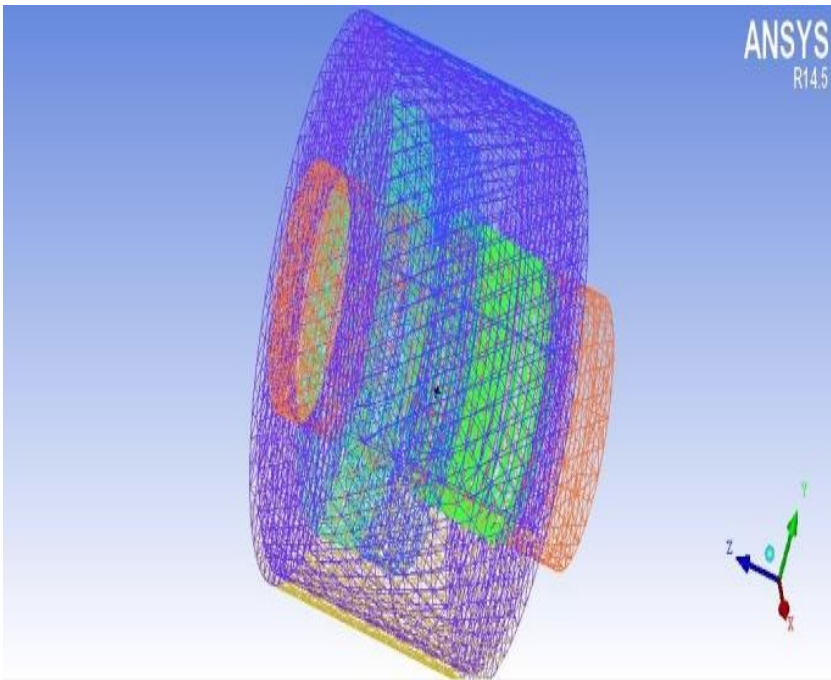

Fig-5 (A): Surface meshing (with housing) of Mechanical seal.

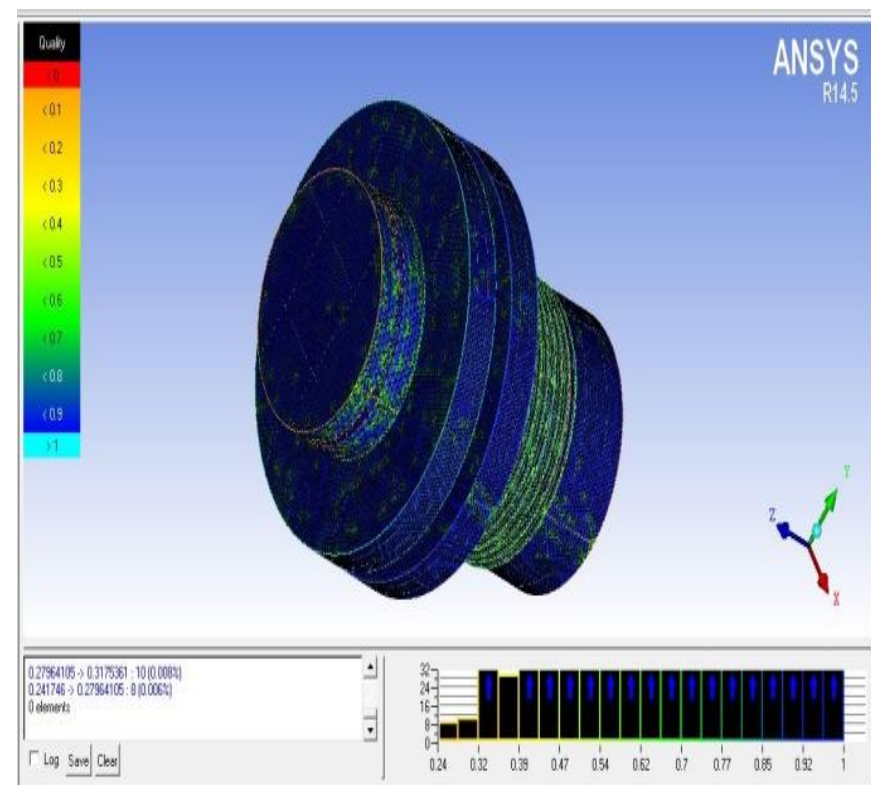

Fig-5(B): Volume meshing (without housing) of Mechanical seal.

\section{RESULTS AND DISCUSSION}

After performing simulations, theoretical and the numerical values for heat transfer rate was calculated. It was found that using composite ring as a mating ring, rate of heat transfer was increased reducing the temperature of the seal face. The variation in heat flow simulated using ANSYS Mechanical Module 14.5 for different mating rings is shown in figures 6(a) and 6(b). The simulation performed using CFD FLUENT shows approximate near values as observed using ANSYS Mechanical Module 14.5. The comparison between the graphs generated for the simple material mating made of carbon graphite and the composite ring made of carbon graphite and silicon carbide was observed. The temperature drop for the mating rings along the radius is shown in the graph in figures 7(a) and 7(b).

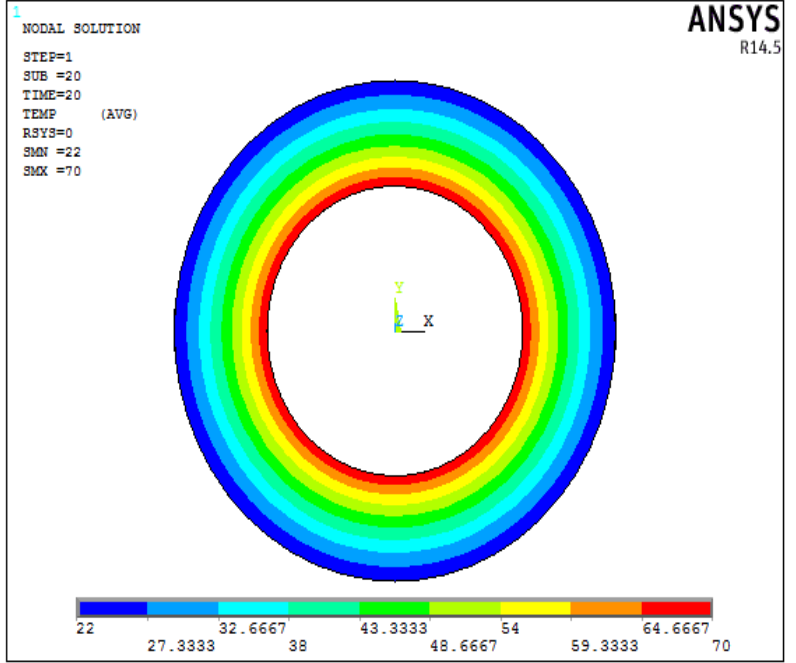

Fig-6 (a): Simulated interface temperature for simple ring.

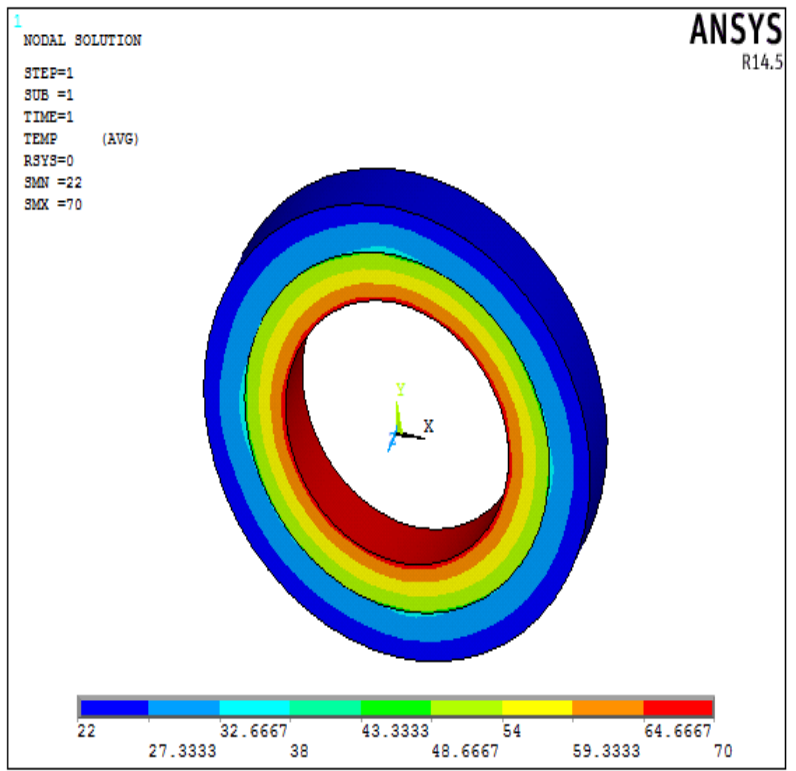

Fig-6 (b): Simulated interface temperature for composite ring.

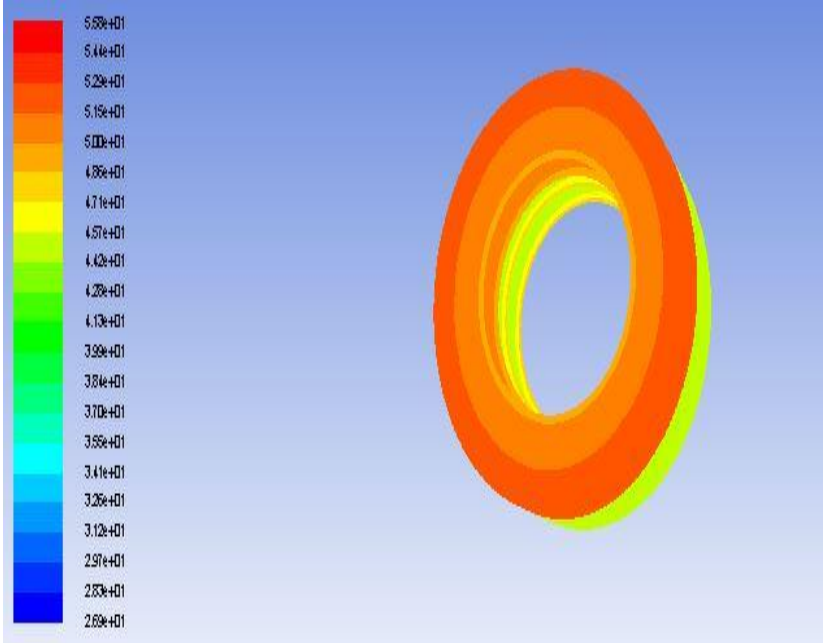

Fig-7: Temperature distribution in mechanical seal with composite mating Ring. 


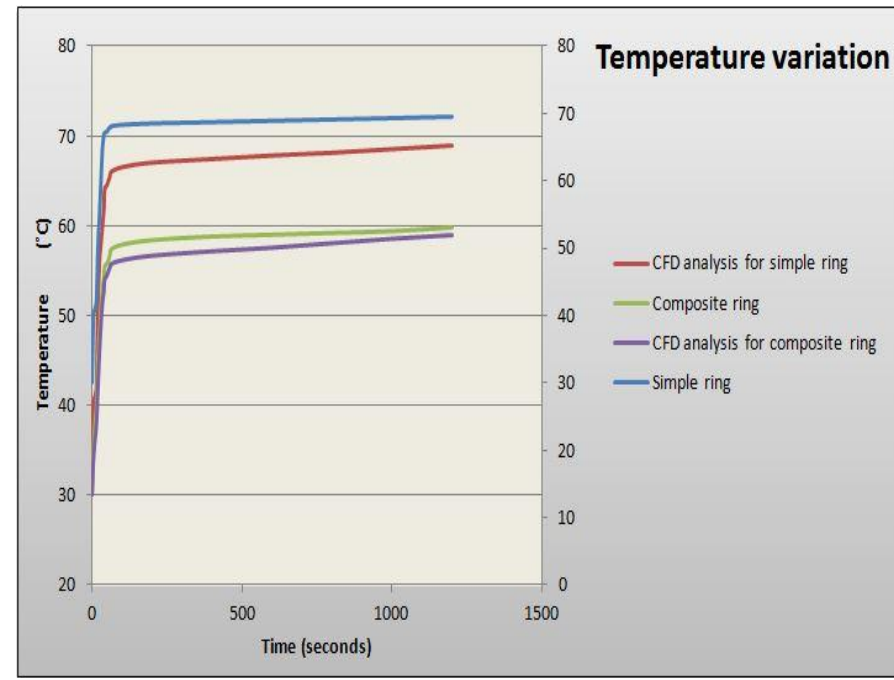

Fig-8 (a): Temperature variation with Time for Mating Rings.

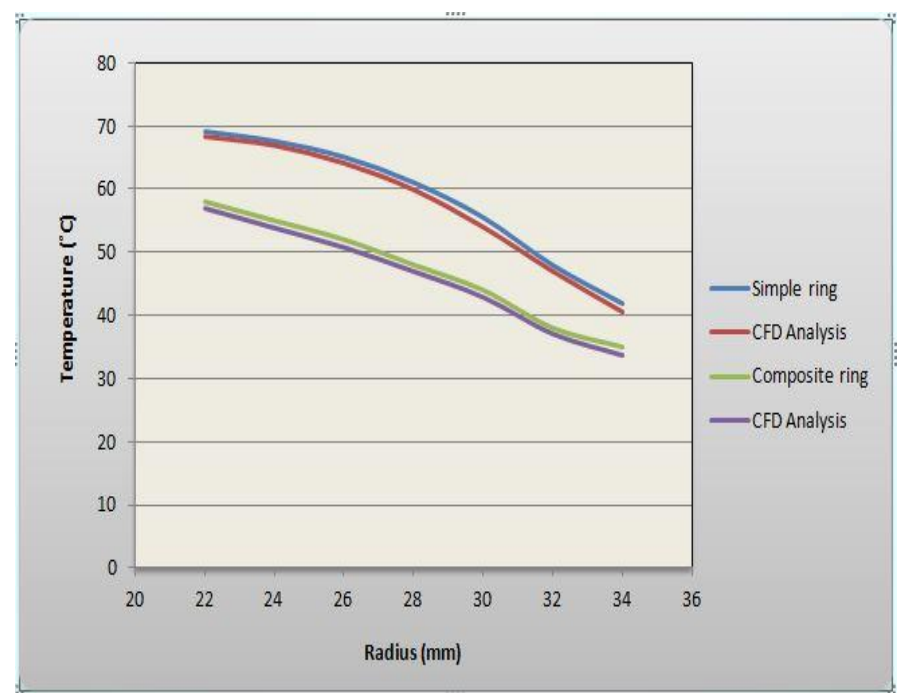

Fig-8 (b): Temperature variation with Radius for Mating Rings.

\section{CONCLUSION}

Heat removal is very important during mechanical seal operation for better seal performance. Thus, alternative heat augmentation techniques are highly desirable. CFD simulations are performed to provide evidence of the feasibility of applying the concept of composite ring in the mechanical seal for the purpose to improve heat dissipation through the seal face reducing the seal face temperature. From the above results it may be concluded that the composite mating ring made of different of material having different thermal conductivity can be executed successfully and is effectual in reducing the operating temperature of the seal by increasing heat transfer rate and thus increases the seal's life span. Higher thermal conductivity materials such as silicon carbide is mainly used in industrial applications as heat diffusion rate is faster in these materials as compared to the materials with lower thermal conductivity. Different material combinations having different thermal conductivity can be implemented according application requirement.

\section{REFERENCES}

[1]. Jones, G.A., 2004. On the Tribological Behaviour of Mechanical Seal Faces Material in Dry Line Contact part I. Mechanical Carbon, Wear 25, pp 415-432.

[2]. Wan yi, Xiong Zhangsheng, 2008. The Effect of Laser Surface Texturing on Frictional Performance of Face Seal, International Journal of material processing technology, 197, pp 9-00.

[3]. Lebeck, A.O., Principles and Design of Mechanical Face Seal, Wiley, New York1991.

[4]. Yu XQ, HE 'S and Carl . Frictional Characteristics of Mechanical Seals with a Laser Textured Seal Face. J Mater Proc Tech 2002; 129; 463-466.

[5]. Kennedy FE and Karpy SA. Thermo cracking of a Mechanical Face Seal. Wear 1982; 79: 21-36.

[6]. Khonsari, M.M. and Stephens, S., "A Zero Emission Mechanical Seal with Integrated Micro Heat Exchanger", 2002.

[7]. Etison, I., Kligerman, Y., Halperin, G., "Analytical and Experimental Investigation of Laser Textured Mechanical Seal Faces", Tribology Transactions, vol. 42, Iss. 3, pp 511516, 1999.

[8]. Pascovici, M.D. and Etison, I. "A Thermo Hydrodynamic Analysis of a Mechanical Face Seal", ASME Journal of Tribology, V.114, pp639-645, 1992.

[9]. Buck, S.G., "Materials for Seal Faces", Pumps and systems, pp.22-26, Jan.2001

[10]. Luan, Z. And Khonsari, M.M. Computational Fluid Dynamic Analysis of Turbulent Flow within a Mechanical Seal Chamber. ASME, J.Tribal.2007, 120-128.

[11]. Xiao N and Khonsari MM. A Review of Mechanical Seals Heat Transfer Augmentation Techniques. Recent patents Mech Eng 2013; 6(2): 87-96.

[12]. Buck, S.G., "Estimating Heat Generation, Face Temperature and Flush Rate for Mechanical Seals", Proceedings of pump users Expo'99, pp.167-172, 1999.

[13]. Phillips, R.L., Jacobs, L.E., Merati, P.," Experimental Determination of the Thermal Characteristics of a Mechanical Seal and Its Operating Environment", Tribology Transaction, Vol. 40, Iss 4, pp. 559-568, 1997.

\section{BIOGRAPHIES}

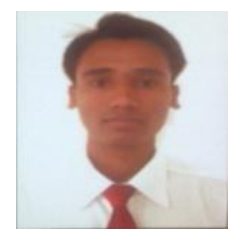

Lalit Kumar Bajirao Chauhan, M.Tech research scholar (thermal engineering) from Lovely Professional University and his area of interest in research area is thermal consideration in mechanical seal.

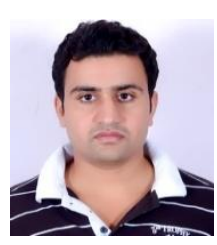

Sandeep Kumar Duran working is an Assistant Professor in Mechanical Department (Thermal Engineering) at Lovely Professional University, Jalandhar. $\mathrm{He}$ is pursuing his $\mathrm{PhD}$ (Bio Fuel) from NIT Jalandhar. He has 3 years experience in research and his area of interest includes heat transfer and Bio Fuel. 